\title{
Poner en crisis a la política, la ética y la estética
}

\author{
Saló o los 120 días de Sodoma | Pier Paolo Pasolini | 1975
}

Isée Bernateau*

Université Paris 7

Recepción: 15 de diciembre de 2019; aceptación: 2 de febrero de 2020

\begin{abstract}
Resumen
Este trabajo analiza psicoanalíticamente el film póstumo de Pasolini, inspirado en la novela Los 120 días de Sodoma, del Marqués de Sade. La trama presenta el increscendo de violencia, que el cineasta italiano ambienta en un marco completamente diferente al del original. Se trata del final de la Segunda Guerra Mundial en Italia, durante la república de Salo, creada por Mussolini en el norte de Italia entre septiembre de 1943 y abril de 1945 . A partir de ese escenario, se aborda la categoría de lo Real irrepresentable como metáfora de los campos de exterminio nazis.
\end{abstract}

Palabras clave: Política | Ética | Estética

Put politics, ethics and aesthetics in crisis

\begin{abstract}
This work psychoanalytically analyzes Pasolini's posthumous film, inspired by the novel The 120 Days of Sodom, by the Marquis de Sade. The plot presents the increscendo of violence, which the Italian filmmaker sets in a completely different framework from the original. It is the end of the Second World War in Italy, during the Salo Republic, created by Mussolini in northern Italy between September 1943 and April 1945. From this scenario, the category of the unrepresentable Real is approached as Nazi death camps metaphor.
\end{abstract}

Keywords: Politics | Ethics | Aesthetics

Un día antes de su asesinato, Pasolini declaró al periodista que lo entrevistaba a propósito de la que sería su última película, Saló o los 120 días de Sodoma: "Escandalizar es un derecho; escandalizarse es un placer”. $\mathrm{Y}$ en efecto, esta película es como mínimo escandalosa. El largometraje, inspirado en la no menos tumultuosa novela Los 120 días de Sodoma de Sade (1785), elige respetar escrupulosamente el crescendo de violencia del original pero sitúa la acción en una época completamente diferente: hacia el final de la Segunda Guerra Mundial, durante la república de Saló, en el corazón de la república fascista promulgada por Mussolini en Italia del Norte, entre septiembre de 1943 y abril de 1945. En la película de Pasolini, el castillo de Silling, que Sade ubica "fuera de Francia, en un lugar seguro, al fondo de un bosque inhóspito, en un reducto al que solo pueden acceder los pájaros del cielo por todos los cuidados tomados", es reemplazado por un palacio al norte de la ciudad de Saló, una sublime villa palladiana donde jóvenes mujeres y hombres serán secuestrados y encerrados para siempre. Son entregados a sus cuatro verdugos, cuatro fascistas, cuatro "poderosos": un duque, un banquero, un magistrado y un obispo; y a cuatro madamas y "narradoras", encargadas de relatar las agresiones y crímenes sexuales. En la intimidad de este universo cerrado perfectamente aislado, los cuatro poderosos destruirán a sus víctimas sistemáticamente. Pasolini se encargó de aclarar que estos poderosos "se comportaban con sus víctimas exactamente de la misma manera que los nazi-fascistas con las suyas" (Pasolini, 1975, p. 20).

La película se divide en cuatro partes, siguiendo el modelo de La Divina comedia de Dante: el Vestíbulo del infierno, el Círculo de las pasiones, el Círculo de la mierda y el Círculo de sangre. Se aprecia muy nítidamente un antes y un después: el mundo del antes es el del principio de la película, el mundo del afuera, del lago de Garde, el pasto verde y el cielo azul. El mundo del después es el mundo puertas adentro, el de la villa

* isee.bernateau@orange.fr 
palladiana, ese lugar de alta cultura transformado en lugar límite, lugar final de todo lugar; es decir, un lugar donde lo imposible tiene lugar, el lugar de lo destruido pero también de lo que ya no está. Así le dice un verdugo desde el balcón a una de sus víctimas, cuando aún se encuentran en el jardín: "para el mundo exterior, ustedes ya están muertos". Un lugar de muertos andantes, de muertos sin sepulturas. La villa es un lugar límite como lo fueron los campos de exterminio, un lugar donde se cancela la posibilidad misma del lugar como garante de existencia para los vivos y de sepultura para los muertos. Sin esta garantía, el lugar, la imagen de la villa que cierra sus puertas para siempre, corre el riesgo de volverse el lugar que dañará violentamente a la humanidad.

Llegados al Vestíbulo del infierno, uno de los verdugos pregunta: "¿no habría que mirarlos un poco mejor?" y otro ordena: "Sáquense la ropa". Levanta brutalmente el buzo de una de las jóvenes, le descubre los senos y baja el pantalón de un joven para desnudar su pene. Una de las cuatro narradoras baja la bombacha de una de las adolescentes, Eva, y le intima: "Mostrale a estos buenos señores lo que escondés abi debajo; miren esa pequeña maravilla, un culo firme como nunca se vio". Eva baja la mirada, llena de vergüenza. Las bien llamadas "partes íntimas" son exhibidas ante todas las miradas, infringiendo de facto la intimidad corporal, que solo la vergüenza protege, verdadera "centinela que custodia las fronteras de lo intimo, que señala y castiga cualquier violación de sus fronteras", como afirma Claude Barazer (2002, p. 117). Y agrega: "uno de los motores del júbilo perverso es sin duda la caída del objeto íntimo, ya sea propio o del otro. La vergüenza trasladada a la víctima es esencial para el júbilo del perverso" (Barazer, 2002, p. 117).

Vemos en el "Círculo de las pasiones" y en el "Círculo de la mierda”, el meollo de la película, cómo reducen la intimidad más recóndita de las víctimas a nada. En el salón principal, los relatos de las madamas-narradoras a verdugos y víctimas narran lo que normalmente se calla en sociedad: los detalles sexuales más íntimos de cada relación sexual. Uno de los fascistas enuncia catedráticamente una de las reglas: "No se debe menospreciar ningún detalle. Solo de esa manera podremos encontrar en sus historias las formas de excitación que esperamos de ellas". Se trata por lo tanto de decirlo todo, pero también de mostrarlo todo y sobre todo de hacerlo todo, hacerlo todo para que sea visto, condición para el júbilo perverso de los verdugos.
El ataque a las víctimas adquiere formas insólitas, dando lugar a las mayores crueldades: los verdugos sodomizan en público a los y las adolescentes, los masturban, les enseñan a masturbarse con un muñeco, casan a dos de ellos a la fuerza para presenciar y participar de la noche de bodas, los hacen caminar desnudos en cuatro llevados con correa y haciéndoles comer pedazos de carne de un plato, los miran mear y cagar, los obligan a guardar y mostrar sus excrementos todas las mañanas, les pegan si se limpiaron el culo y todas las mañanas verifican que estén bien sucios; los hacen comer su mierda, los acuestan con la cara en el piso y el culo levantado para organizar exposiciones de culo que observan con linternas. Una de las jóvenes les suplica: “;Mátenme! ; Mátenme antes de deshonrarme! Dios al menos podrá apiadarse de mí. Mátenme para liberarme del tormento de ver y escuchar tanto horror".

En Saló, el control totalitario de los verdugos sobre las víctimas es absoluto, sin que nada escape a su poder. Las víctimas deben pertenecerles, en cuerpo y alma, body and soul. Deben sobre todo perder su estatus de sujetos deseantes para volverse solamente "objetos" de deseo, seres a los que se les puede hacer lo que sea y hacerles hacer cualquier cosa, seres sometidos desde la decadencia, la deshumanización, tal como esa imagen de las víctimas en cuatro llevadas como perros con correa. La destrucción de la alteridad del objeto es posible gracias a un régimen escópico de aterradora eficacia. Al querer verlo todo, mirarlo todo, y más aún lo que normalmente no se muestra a nadie, los verdugos destituyen a sus víctimas de la posición de sujetos para reducirlos al estado de objetos, atrapados en las redes de la mirada depredadora que funciona como trampa alienante y deshumanizante. $\mathrm{Al}$ igual que en el Panóptico, esa cárcel pensada por Bentham y de la que Foucault (2002) reveló las implicaciones políticas, se trata de "inducir un estado consciente y permanente de visibilidad en el detenido que garantiza el funcionamiento automático del poder" (p. 185). Agrega Foucault (2007):

El verdadero efecto del Panopticon consiste en ser de tal manera que, aún cuando no haya nadie, el individuo en su celda no solo se crea sino se sepa observado, que viva la experiencia constante de encontrarse en un estado de visibilidad para una mirada. (p. 99)

La esencia misma de este régimen escópico es totalitaria: "Percibirlo todo a través de una única instancia, es decir, un solo punto de vista, un poder central para dominar, controlar" (Gantheret).

Pero la fuerza de la película de Pasolini reside en la deformación al extremo de este régimen escópico hasta 
poner al espectador en una posición radicalmente insoportable. Al ver las víctimas hacerse sadizar, el espectador se coloca al mismo nivel que los verdugos, mientras que la cámara de Pasolini está claramente del lado de las víctimas y el espectador solo puede identificarse con ellas. Los primeros planos de los rostros de las jóvenes mujeres y los jóvenes hombres muestran una desesperación que genera una compasión inmediata. La paradoja que hace de Saló una película única en cuanto a su representación es la de ser inmirable: está compuesta de imágenes que no podemos mirar y que sin embargo recibimos como golpes de puño. El espectador debe enfrentar el insoportable calvario de una sucesión inexorable, de círculo en círculo, hasta llegar a la muerte de todas estas jóvenes víctimas, sufriendo suplicios inéditos que vemos a través de binoculares. En la última parte de la película, la paradoja alcanza su punto cúlmine: el ojo del espectador se funde con el del verdugo voyeur, cómodamente sentado en un sillón: con binoculares, mira cómo sus compañeros torturan y matan a las víctimas mientras masturba a uno de los chicos sentado a su lado. El espectador debe ocupar ese lugar, un lugar inaguantable e insoportable que no puede desocupar de ninguna manera y es forzado a hacerlo.

No hay manera de que el espectador pueda ser cómplice complaciente de la violencia infligida. Si bien Saló es una película sobre el voyeurismo, no es un film voyeur: el espectador nunca podrá disfrutar de lo que está viendo; al contrario, vive la experiencia límite de lo insoportable para la vista. Y Pasolini busca claramente lo insoportable (cito):

La figura principal (de carácter metonímico) es la acumulación (de crímenes); pero también la hipérbole (quisiera llegar al límite de lo aguantable)". El espectador que debe enfrentar tamaño desafío podría recurrir a la frialdad o incluso a la indiferencia, pero estas posturas le son prohibidas ya que aumentarían "la distancia cínica y apática adoptada por los fascistas. (Veire, 2007, p. 119)

De repente, el espectador no solo se escandaliza: lo atacan con violencia en su intimidad, obligado a mirar un espectáculo insostenible, sin ser complaciente ni cínico. "Es la película más dura, más angustiante, más desafiante que dirigí hasta hoy", le confiesa Pasolini al periodista el día anterior a su asesinato, el 31 de octubre de 1975. En el dossier de prensa que acompaña a la película en el estreno, Pasolini escribe: "Con atrocidades casi insólitas, casi imposibles de contar, toda la película se presenta como una enorme metáfora sádica de lo que fue la disociación nazi-fascista con sus crímenes contra la humanidad".
Con Pasolini, denunciar el fascismo también implica denunciar el capitalismo, en el que los cuerpos se reducen al estado de mercancías y se destruyen las fuerzas vivas de la sexualidad. Al contrario de lo que ocurre en la trilogía de la vida de Pasolini, el Decameron (1971), los Cuentos de Canterbury (1972) y las Mil y una noches (1974), películas donde la sexualidad es sinónimo de alegría y de liberación, el sexo en Saló ocupa el lugar de la dominación y la opresión más cruel.

Dos grupos humanos se oponen y se enfrentan a lo largo de toda la película. Por un lado, los que Pasolini llama los "poderosos y ricos", aquellos que pueden "armar su sueño con toda impunidad". Y del otro, las chicas y los chicos, los adolescentes raptados del pueblo, desgarrados de sus vidas para ingresar a un suplicio interminable de secuestro, tortura y asesinato del que nadie escapará. Cuando sale la película, Serge Daney (1980) señala en los Cabiers du cinéma que existe una "heterogeneidad fundamental” entre estos dos grupos. En su opinión, se debe a que (cito) "hay un acceso simple del pueblo al placer, algo que sucede sin que nada ni nadie pueda darle inicio; en cambio, los amos desean desear" (s/d). En efecto, durante el Círculo de sangre, la última parte de la película, la "solución final", es decir el exterminio puro y simple de las víctimas adquiere la forma de una expedición punitiva que castiga a todas aquellas y aquellos que intentaron preservar un atisbo de intimidad dentro de este lugar infernal. Se los acusa del crimen de haber querido resguardar alguna intimidad sexual que escape de la mirada de los verdugos y de su júbilo. Dentro de la villa palladiana como lugar límite, donde se elimina la posibilidad de cualquier vida humana civilizada y donde por lo tanto lo imposible sucede, ocurre la destrucción sistemática de lo que Piera Aulagnier (2009) llama "el derecho al secreto", la "condición vital para el funcionamiento del Yo" (p. 17). Ninguna vida psíquica es posible sin intimidad, sin constituir un espacio protegido al que nadie tenga acceso.

Una joven escondió una foto de su novio debajo del colchón. Cuando los verdugos la amenazan para que la entregue, denuncia a otras dos chicas para intentar salvarse, sabiendo que el castigo que las espera puede ser mortal. En la secuencia siguiente, vemos esas dos jóvenes haciendo el amor, mientras que una susurra amore en el oído de la otra. Uno de los verdugos somete a una de ellas, ante la mirada horrorizada de su amante. Enfrentada al cañón del revolver, denuncia a Ezio, uno de los chicos, para intentar salvar su vida. En el siguiente plano, Ezio hace el amor con la sirvienta negra que sirve las co- 
midas durante toda la película. Justo antes de que lo maten, Ezio se levanta, completamente desnudo, y levanta el puño en señal de rebeldía. La imagen atrapa y maravilla: los sacrificados que se rebelan irreductiblemente, el contrapunto ante la corrupción de la inocencia de los otros adolescentes, la misma corrupción que los vuelve "colaboracionistas" y los hace denunciar a sus semejantes para seguir en vida.

Serge Daney (1980) lo hace evidente: no hay complicidad entre los grupos de verdugos y de víctimas. Unos son opresores y otros oprimidos, una diferencia tan radical que se transforma en heterogeneidad de especie. Pasolini logra tal grado de violencia al criticar el fascismo inherente al capitalismo porque recupera la crueldad y la literalidad de la pesadilla de Sade. Ya lo afirmaba Barthes (1976): aunque nazca de una metáfora (Los 120 dias de Sodoma de Sade en tanto metáfora de los campos de exterminio nazis), Saló es un film literal, rigurosamente desprovisto de todo carácter simbólico o alegórico. Cito:

Estas escenas tienen una triste belleza, helada, exacta, como grandes páginas enciclopédicas. ¿Hacer comer excrementos? ¿Vaciar un ojo? ¿Poner agujas en una comida? Lo vemos todo: el plato, el excremento, la mugre, el paquete de agujas, el grano de polenta; como se dice, no nos mezquinan nada (tal como la divisa de Sade). Ante tan absoluto rigor, lo que fundamentalmente se desnuda no es el mundo dibujado por Pasolini, es nuestra mirada: nuestra mirada al desnudo, como efecto de la letra .(s/d)

$¿$ Desnudar nuestra mirada no es precisamente la ambición de Pasolini, logrando con su última obra maestra la proeza de una película al desnudo, que obliga al espectador a mirar a los ojos el mismísimo corazón de lo impresentable, como Malcolm McDowell en La naranja mecánica (1971)? Saló es una película que aborda lo impresentable en lo político, lo ético y lo estético, tal como propone el bello título de este coloquio. Impresentable en primer lugar por su extrema violencia, su crueldad: todos los cineastas y críticos reconocen que esta película alcanza un punto límite del cine, que nunca había sido tocado y que tampoco fue tocado nuevamente. Impresentable también porque versa sobre lo Real, en su sentido lacaniano; intentaremos más adelante definir los contornos de ese Real. Impresentable por representar metafóricamente los campos de exterminio nazis, campos secretos y escondidos de forma deliberada desde la concepción misma, ocultando y borrando políticamente los rastros del crimen. "Malogrado como representación (de Sade o del sistema fascista), el film de Pasolini se transforma en un oscuro reconocimiento de lo que a todos nos cuesta asimilar, y que indudablemente nos molesta [...]. Es por esta razón que me pregunto si el Saló de Pasolini, al cabo de una larga cadena de errores, no es en resumidas cuentas un objeto propiamente sadiano, irrecuperable: en efecto, nadie parece poder recuperarlo”, escribe Barthes. Más allá de la metáfora concentracionaria, más allá de la denuncia del capitalismo que reduce los cuerpos a una condición mercantil, ¿qué será entonces que nos tienen que mostrar a toda costa?

Sin duda, quieren mostrarnos en primer lugar el detrás de escena, lo que normalmente se disimula, o incluso se borra de la conciencia. Pasolini, al elegir como única locación de la película una sublime villa palladiana con las paredes cubiertas de obras de arte, se hace cargo de mostrar el trasfondo barbárico de la cultura, los cimientos sangrientos de las conquistas a priori más refinadas de la civilización. En ese sentido, Saló o los 120 días de Sodoma invierte totalmente el proceso civilizatorio descrito por Freud en el sorprendente texto El malestar en la cultura (1930). En vez de acoplarse al proceso que lleva a los hombres a renunciar a la ferocidad en pos de la seguridad encontrada en la comunidad humana al igual, a decir verdad, que toda la producción cinematográfica mainstream, el gesto pasoliano, idéntico al gesto freudiano del Malestar, procede exactamente al revés para que aparezca implacable y ciegamente el meollo de odio y violencia inherente a cualquier vínculo humano. Este movimiento inverso es particularmente notorio en el "Círculo de la mierda", un círculo de los más difíciles de mirar y tolerar, en el cual víctimas y verdugos comen mierda (que era en realidad el mejor chocolate italiano, según contaron los actores más tarde), de buena o mala gana. Durante la cena de casamiento de las dos jóvenes víctimas, el ritual sagrado del casamiento es perfectamente mimado así como violentamente profanado por verdugos y madamas. Las jóvenes mujeres desnudas solo sirven mierda, en una bella loza blanca. La cámara pasoliana alterna planos largos y planos cortos desgarradores de los rostros de las víctimas, avergonzadas y devastadas por su propia decadencia. Una de esas víctimas, con el rostro deshecho y un tenedor lleno de mierda en la mano, le confiesa a su amiga: "Eva, no puedo". Eva le responde luego de forzarse a tragar un bocado, con un irreprimible gesto de asco: "Hacelo por la Madona". Uno de los verdugos obliga al joven, vestido de novia para la ocasión, a comer mierda. Le mete cucharadas de mierda en la boca, alentándolo a juntar fuerzas para su noche de bodas: "no bay nada peor que un aliento sin 
olor". En la escena siguiente, el mismo verdugo sube las escaleras con el recién casado y con los labios y el mentón llenos de mierda, lo besa apasionadamente. El joven mira al verdugo con incomprensión y desesperación, mientras una lágrima, absolutamente pura, desliza por su mejilla.

Con su pasión por la mierda, los verdugos y madamas embisten uno de los bastiones más intangibles de la civilización. Desde el principio y hasta el final de su obra, Freud consideró la represión de la coprofilia como fundadora de la humanidad tal como la conocemos. Según su hipótesis, la represión olfativa, una de las represiones más potentes, ocurrió cuando el ser humano se irguió, abandonando la postura de cuatro patas por la de dos. En las Cinco conferencias sobre psicoanálisis de 1910, Freud asocia la represión de las mociones coprófilas con la represión de los deseos incestuosos (cito): "Son sobre todo las mociones placenteras coprófilas de la infancia, vale decir las que tienen que ver con los excrementos, las afectadas de la manera más radical por la represión; además, la fijación a las personas de la elección primitiva de objeto". Al poner en escena una sexualidad coprófila y absolutamente transgresora, Saló o los 120 días de Sodoma obliga al espectador a suspender violentamente una represión que funda su humanidad: el rechazo de la animalidad y la prohibición del incesto. El carácter impresentable de la película se debe en gran parte a este sabotaje de la represión, esa manera de filmar lo que nunca se filma, o que en todo caso nunca se filma así; con esa frialdad de literalidad enciclopédica, tan bien señalada por Barthes. Una frialdad glaciar que inmoviliza al espectador como una mariposa clavada en una caja. Pero una vez más, ¿qué nos pusieron frente a nuestros ojos?

Pasolini, al operar semejante anulación de la represión, obliga al espectador a mirar de frente al escándalo de lo sexual directamente relacionado con la muerte. "El impulso de amor, llevado hasta el extremo, es un impulso de muerte" (Bataille, 1990, p. 29), escribe Bataille en $E l$ erotismo. Profundizando la línea de Bataille, y a sabiendas de que la esencia misma de la sexualidad humana está relacionada con el incesto y el asesinato, Lacan (1964) afirma que "la presencia del sexo en lo viviente está ligada a la muerte" (p. 66). Y eso es precisamente lo que vemos en Saló o los 120 días de Sodoma: ese sexual de muerte, violento y destructor, que no le importa el objeto en lo más mínimo, que gusta de las peores vilezas, que goza de su propia crueldad y ultraja la intimidad del otro y la de sí mismo hasta destruir el objeto habilitante del goce. Respecto del amor al prójimo, Freud (1930) advierte en El malestar en la cultura:

la verdad oculta tras de todo esto, que negaríamos de buen grado, es la de que el hombre no es una criatura tierna y necesitada de amor, que sólo osaría defenderse si se le atacara, sino, por el contrario, un ser entre cuyas disposiciones instintivas también debe incluirse una buena porción de agresividad. Por consiguiente, el prójimo no le representa únicamente un posible colaborador y objeto sexual, sino también un motivo de tentación para satisfacer en él su agresividad, para explotar su capacidad de trabajo sin retribuirla, para aprovecharlo sexualmente sin su consentimiento, para apoderarse de sus bienes, para humillarlo, para ocasionarle sufrimientos, martirizarlo y matarlo. Homo homini lupus.

Esta visión pesimista es para Freud la culminación de un largo trayecto especulativo. En Tres ensayos, Freud (1905) ya advertía que la pulsión contenía una parte agresiva (cito):

La sexualidad de la mayoría de los varones exhibe un componente de agresión, de inclinación a sojuzgar, cuyo valor biológico quizá resida en la necesidad de vencer la resistencia del objeto sexual también de otra manera, no sólo por los actos del cortejo.

Partiendo de esta dimensión agresiva, intrínseca de la pulsión sexual activa, Paul Denis llegará al par dominación [emprise] y satisfacción, la dominación definida como la búsqueda activa de control del objeto en pos de obtener alguna satisfacción (siempre pasiva, en oposición a la dominación) de él. El interés heurístico de este par se debe a su dialéctica: cuanto mayor es la dominación, menor es la satisfacción, e inversamente, ya que en el mejor de los casos, la satisfacción limitará el esfuerzo de dominación.

Bajo este punto de vista, es evidente que Saló o los 120 días de Sodoma es la puesta en escena de una pesadilla de la dominación cuya forma radical y extrema desemboca en un "amor con semilla asesina, prototipo de todo amor donde reside en lo más íntimo la pulsión de muerte”, como escribe François Gantheret. Solo la muerte del objeto, magistralmente escenificada en el "Círculo de sangre", será susceptible de frenar la locura de la dominación, ya que al fin y al cabo, la dominación lucha contra la independencia del objeto; es decir, contra el hecho de que el objeto siempre es susceptible de escurrirse del sujeto, de rechazarlo, de escaparle.

Se hace difícil de esta manera establecer si esa dominación está al servicio de Eros o Thanatos. Freud (1926) señala en Inbibición, sintoma y angustia que "el Eros quiere tocar porque aspira a la unión, a borrar las fronteras espaciales entre el yo y el objeto amado. Pero tam- 
bién aspira a la destrucción, ya que antes de la invención del arma a fuego, solo podía darse a proximidad. Presupone necesariamente el contacto corporal, tocar al otro". En efecto, la pulsión de vida y de muerte precisan ambas de la pulsión de dominación, se intrican, se enredan, se entregan incluso a la dominación casi indistintamente, como se advierte en las salidas más audaces de Más allá del principio de placer (1920). Pero tal como expresa Paul Denis, "pensamos que la idea de la libido que mata si no se detiene el desencadenamiento del sadismo en tanto fuerza libidinosa fue un objeto escandaloso, incluso para Freud, y fue neutralizado al invocar la pulsión de muerte”. ¿El verdadero escándalo no reside más bien en plantear la posibilidad de una "libido que mata" solo por el placer de poseer y subyugar el objeto, y no que el objetivo de toda vida es la muerte? En ese sentido, Saló es realmente una obra que pone en crisis a la política, la ética y la estética, ya que ataca los cimientos fantasmáticos de la opresión política, a través de la metáfora sadiana. La equivalencia entre totalitarismo y sadismo es demasiado grosera para que nos pueda engañar, y Pasolini alertó al espectador sobre esto en cada entrevista que dio sobre la película. No obstante, Saló también exhibe con implacable nitidez ese plus de placer sexual involucrado en la agresión y destrucción del otro en sus variantes más extremas.

Uno de los enigmas de Saló o los 120 días de Sodoma es entender por qué condena al espectador a ese suplicio de una hora 51 minutos del que no se puede escapar, salvo abandonando la sala como hizo la mayoría cuando salió la película. En mi caso, reconociendo la fuerza e importancia de este film, tuve que verla en partes para poder terminarla, en intervalos de 5 a 10 minutos por día, tal era la violencia que ejercía en mí. Y solo lograba ver esos 10 minutos si tomaba notas detalladas de cada secuencia, alegando razones científicas, pero era en realidad la manera de desviar mis ojos de lo que veía. Corine Rondeau examina el carácter excepcional de este ataque al espectador. Llega a la hipótesis de un pacto con la vergüenza, donde el espectador reconoce, bien a su pesar, que "someterse a estas imágenes permite que existan para sacarles provecho en lo referido a la dominación; por lo tanto, se realiza un pacto. La vergüenza reside en gozar con lo que se está viendo, es decir, en no poder renunciar

Traductor: Federico Gianotti a lo insoportable”. En efecto, ¿qué fuerza me alentaba a volver a reproducir el DVD una y otra vez para llegar a la última secuencia de la película? Un final donde se ve a dos jóvenes milicianos que vieron la sucesión de torturas $\mathrm{y}$ asesinatos desde una ventana en el patio junto a los verdugos; prenden la radio, bailan tímidamente un vals y mantienen el increíble diálogo final que concluye la película: ¿Cómo se llama tu novia? Margherita. ¿Por qué ese final, y qué aporta sobre el conjunto de este suplicio hecho película?

Es la puesta en escena de la complicidad indiferente y bromista de los milicianos, los colaboracionistas, kapos transformados en semejantes de los guardias de los campos de concentración, de quiénes se supo que vivían al lado de las barracas y los hornos crematorios, organizando fiestas a la noche o los fines de semana. Por "mise en abyme", esa complicidad indiferente involucra a los espectadores que participan de esa masacre generalizada al ver la película. Me pregunto entonces si Pasolini, poniendo en crisis el "espectáculo" que su película propone con tanta fuerza, no busca al fin y al cabo proponer o provocar un sobresalto en el espectador, haciéndole sentir en sus entrañas lo insoportable de su participación en la destrucción de los humildes, de las víctimas, aún siendo pasiva.

Para terminar, quisiera mencionar que pese a toda la crudeza que ejerce sobre el espectador, Saló o los 120 días de Sodoma rescata el amor, el amore susurrado entre las víctimas, ese amore que hace que se encuentren a la noche para hacer el amor, fare l'amore en el secreto y la dulzura de la intimidad protegida. Solo ese amore, privilegio de los humildes, de aquellos que no tienen el poder para oprimir al otro, puede escaparle a los verdugos narcisistas y todopoderosos, limitándoles así su poder de destrucción. Aunque parezca insólito, Saló, así como la trilogía de la vida, rinde un homenaje desesperado al amor, el amore que ya no puede ignorar que el lado oscuro de lo sexual es destructivo, pero puede sin embargo preservar el objeto, arriesgándose a amarlo por lo que es y no por lo que le podemos hacer o hacer hacer. La libertad de los enamorados, en esa precariedad de la villa paladiana, espejo de nuestro mundo de ruido y furia, es para Pasolini, en el umbral de su muerte violenta, lo más preciado. 


\section{Referencias}

Aulagnier, P. (2009). «Le droit au secret : condition pour pouvoir penser » ["El derecho al secreto: condición para poder pensar"]. En Piera Aulagnier et al., La pensée interdite, París: Puf, Petite Bibliothèque de psychanalyse.

Barazer, C. (2002). «Tactique russe » [“Táctica rusa”]. Champ psychosomatique 27(3).

Barthes, R. (1976). Comentario para Le monde.

Bataille, G. (1990) El erotismo. Barcelona: Tusquets. Traducción de Pierluigi Cerri.

Daney, S. (1980). Cabiers du Cinéma, (308).

Foucault, M. (2002). Vigilar y castigar: nacimiento de la prisión, Buenos Aires, Siglo XXI. Traducción de Aurelio Garzón del Camino.

Foucault, M. El poder psiquiátrico. Buenos Aires: Fondo de Cultura Económica. Traducción de Horacio Pons.

Freud, S. (1905). Tres ensayos sobre la teoría sexual. Buenos Aires: Amorrortu.

Freud, S. (1909). Cinco conferencias sobre psicoanálisis. Buenos Aires: Amorrortu.

Freud, S. (1920). Más allá del principio de placer. Buenos Aires: Amorrortu.

Freud, S. (1926). Inbibición, sintoma y angustia. En Obras Completas, Volúmen XX. Buenos Aires: Amorrortu.

Freud, S. (1930). El malestar en la cultura. Austria: Alianza Editorial.

Grimaldi, A. (productor) y Pasolini, P.P. (director). (1971). Il Decameron [cinta cinematográfica]. Italia: United Artists.

Grimaldi, A. (productor) y Pasolini, P.P. (director). (1972). I racconti di Canterbury [cinta cinematográfica]. Italia: United Artists.

Grimaldi, A. (productor) y Pasolini, P.P. (director). (1974). Il fiore delle Mille e una notte [cinta cinematográfica]. Italia: United Artists.

Grimaldi, A. (productor) y Pasolini, P.P. (director). (1975). Salo ou les 120 journées de Sodome [cinta cinematográfica]. Italia-Francia: Produzioni Europee Associete; Les Productions Artistes Associés.

Hagg, R., Sheilds, P. (producción) y Kubrick, S. (dirección). (1971). La naranja mecánica. Reino Unido/Estados Unidos: Warner Bros y Hawk Films.

Lacan, J. (1964). El seminario libro XI. Cuatro conceptos fundamentales del psicoanálisis. Buenos Aires: Paidós. Traducción de Juan Luis Delmont-Mauri y Julieta Sucre.

Pasolini, P.P. (1975). Salo ou les 120 journées de Sodome. dossier de prensa en francés.

Sade, D.A.F. (1785). Les Cent Vingt Journées de Sodome. Francia.

Veire, V. (2007). Prenez et mangez, ceci est votre corps [Tomen y coman, este es su cuerpo]. Bruselas: La lettre volée. 